\title{
Human immunodeficiency virus (HIV) infection, sexually transmitted diseases and HIV-antibody testing practices in Belgian prostitutes
}

\author{
R Mak, J Plum, L Van Renterghem
}

\begin{abstract}
From December 1988 to April 1989, 154 female prostitutes in and around Ghent, Belgium, were interviewed about their knowledge, attitudes and practices in relation to the risks for sexually transmitted diseases (STD) and human immunodeficiency virus (HIV) infection in their profession. Thirty four women worked as window prostitutes, 120 picked up their clients in bars, clubs, and saunas. Blood samples were taken from 123 women. One $(0.8 \%)$ was seropositive for HIV1, $19(15.4 \%)$ had Hepatitis B core antibodies (anti-HBc), eight $(6 \cdot 4 \%)$ showed markers of syphilis. None of them were Hepatitis $B$ surface antigen (HBsAg) carriers. Hepatitis $C$ antibodies (anti-HCV) were present in the serum of three women $(2 \cdot 4 \%)$. Overall STD seroprevalence was higher in the group of window prostitutes than in the group of club prostitutes. One woman admitted intravenous drug use.

Former testing for anti-HIV antibodies had been performed in $102(66.5 \%)$ respondents, of whom $84(82.3 \%)$ were tested in the year preceding the interview. In $74.5 \%$ of the cases, these tests were requested by the women themselves.

These results suggest that HIV infection is not yet prevalent in non-intravenous drug using prostitutes in Ghent, but that this situation may change considering their higher rates of past STD. Window prostitutes are at higher risk than club prostitutes. Testing for HIV seems to be common practice, mostly at the request of the women themselves. Health education should discourage the notion of testing as an alternative to using condoms.
\end{abstract}

Department of Hygiene and Social Medicine R Mak

Department of Microbiology, University Hospital, Ghent State University, Ghent, Belgium J Plum, L Van Renterghem
Introduction

By 30 September 1989, 563 cases of AIDS were diagnosed in Belgium, of which 287 were residents (= more than 5 years living in Belgium), and 276 were non-residents ( $=$ less than 5 years living in Belgium). The number of seropositives is estimated to be around 20,000 , of which 4920 (Sept '89) have been identified. ${ }^{1}$ Male to female ratio is 6.3:1 in AIDS patients and 4.3:1 in seropositives, which illustrates the importance of heterosexual transmission.

Since no vaccine or curative treatment is yet available, these figures are bound to rise in future years. This emphasizes the need for health education on safe sex as the only feasible method of prevention. It should reach in particular all the people who engage in risk behaviour for sexually transmitted diseases.

In Belgium the health education campaign for the prevention of HIV infection was merely aimed at the general population (1987). Since risk behaviour is more prevalent in the "risk groups", the need for health education specifically directed towards these groups is obvious. Health education aimed at a specific target group requires several conditions: access to and acceptance by the group, knowledge of the characteristics and the language of the group.

Prostitutes were the target group of this project. A prostitute was defined as a "woman who offers her body to promiscuous sexual intercourse especially for payment". (The Concise Oxford Dictionary). Difficult access to this group is one of the main problems, which is explained by the many illegal aspects of the profession in Belgium. Every action initiated by public services is considered as suspect by the group.

The aim of this study was to overcome these problems, to contact the women, assess actual behaviour and risks in order to create a base for future intervention. A small pilot study with $\mathbf{4 0}$ women in $1986^{2}$ showed the feasibility of our approach.

\section{Methods}

In order to be accepted by the group and to find access to the group, our team included two contact 
persons. One worked as a transvestite and the other is a female social worker who worked with prostitutes for many years.

During their first visit, the contact persons tried to motivate prostitutes to take part in the study. They were asked to recruit colleagues for participation (snowballing). The initial and subsequent contacts took place at the prostitute's workplace during her working hours.

After consent, the prostitute was interviewed by the contact person by means of a questionnaire. In the same week the contact person introduced the doctor, who took a blood sample on the spot and invited the respondents to discuss with him all their questions on the issue of STD and AIDS. Relevant health education material was handed out during this visit.

Testing was done anonymously. A code number was given to the woman when the blood sample was taken and if she wished, she could phone the doctor to get her results. In case of positive tests, the doctor would not counsel through the telephone, but referred the woman to an appropriate health centre. For the research group itself, it was therefore not possible to identify the respondents.

The questionnaire contained questions on knowledge of STD and AIDS, mobility (number of different work addresses), sexual habits, condom use, social factors, HIV testing, history of STD and personal opinions on prostitution. The interviewers used a language adapted to the respondent.

Anti-HIV1 and 2 antibodies were detected with commercial ELISA tests (Enzygnost antiHIV1 + 2). Sera with a positive or borderline result were retested with an ELISA and confirmed with a Western Blot (WB) (Dupont de Nemours). A serum was considered positive for HIV antibodies when both core proteins and envelope proteins of the virus reacted in the Western Blot.

For syphilis screening a combination of two tests was chosen: VDRL, a floculation test with a nontreponemal antigen (DIFCO) and TPHA, a Treponema pallidum haemagglutination test (FUJIREBIO
INC). When one of the screening tests was positive or borderline a third test was done: FTA ABS, an immunofluorescence test (BIOMERIEUX). For Hepatitis B surface antigens (HBsAg) and antibodies (anti-HBs) as well as core antibodies (anti-HBc) were screened. For these tests we used a commercial ELISA (ORGANON). All tests were performed following the manufacturer's instructions. For Hepatitis $C$ we used an enzyme immunoassay for antibody to hepatitis $\mathrm{C}$ virus manufactured by Ortho Diagnostic Systems with recombinant antigens from Chiron Corporation. Statistical tests were performed with the SPSSPC + V2.0 package (Microsoft).

A letter with the most important results and some related health education messages was sent to the participants of the study as feed back.

\section{Results}

In total 240 persons were actually approached by our team, of whom $156(64 \%)$ collaborated. Eighty four persons $(36 \%)$ refused and no data are available on them. They were mainly window and club prostitutes. Most women who refused did not give any specific reason. Statements like: "I am not interested" or "I have no time" were reflections of a general atmosphere of suspicion.

Since only a very limited number $(n=2)$ of the contacted persons were male, the paper deals only with results from female prostitution $(\mathrm{n}=154)$.

From $123(79.9 \%)$ women a blood sample was taken. The principal investigator, who took all blood samples personally, checked for traces of current intravenous drug use on the respondents' bodies. Only one woman had evidence of current use, and admitted intravenous drug use. Tests for $\mathrm{HBsAg}$, anti-HBs, anti-HBc, anti-HCV, VDRL, TPHA, FTA Abs and anti-HIV1 and anti-HIV2 antibodies were performed (table 1 ).

One woman $(0.8 \%)$ had antibodies to HIV1. She is from West Africa. She left her country in 1988 and had been working in Belgium as a club prostitute for 6 months. Seromarkers for Hepatitis B were found in

Table 1 Serologic markers for HIV, Hepatitis B, Hepatitis $C$ and syphilis in female prostitutes in Belgium ( $n=123)$

\begin{tabular}{|c|c|c|c|c|}
\hline Disease & Test & $\begin{array}{l}\text { Number positive } \\
\text { tests }\end{array}$ & $\begin{array}{l}\text { Percentage } \\
\text { of total }\end{array}$ & 95\% C.I. ${ }^{\star}$ \\
\hline HIV & anti-HIV1 & 1 & $0.8 \%$ & $0.0 \%-2.4 \%$ \\
\hline Hepatitis B & $\begin{array}{l}\text { HBsAg } \\
\text { anti-HBs + anti-HBc } \\
\text { anti-HBc alone }\end{array}$ & $\begin{array}{r}0 \\
0 \\
18 \\
2\end{array}$ & $\begin{array}{l}0 \% \\
0 \% \\
14.6 \% \\
1.6 \%\end{array}$ & $\begin{array}{l}0.0 \%-1 \cdot 4 \% \\
0.0 \%-1 \cdot 4 \% \\
8 \cdot 2 \%-21 \cdot 0 \% \\
0.0 \%-3.8 \%\end{array}$ \\
\hline $\begin{array}{l}\text { Hepatitis C } \\
\text { Syphilis }\end{array}$ & $\begin{array}{l}\text { anti-HBs alone } \\
\text { anti-HCV } \\
\text { VDRL/TPHA/FTA } \\
\text { TPHA/FTA }\end{array}$ & $\begin{array}{l}4 \\
3 \\
2 \\
6\end{array}$ & $\begin{array}{l}3.3 \% \\
2.5 \% \\
1.6 \% \\
4.9 \%\end{array}$ & $\begin{array}{l}0.0 \%-7.1 \% \\
0.0 \%-5.0 \% \\
0.0 \%-3.8 \% \\
2.1 \%-9.0 \%\end{array}$ \\
\hline
\end{tabular}

${ }^{\star} \mathrm{CI}=$ confidence interval. 
Table 2 Characteristics of window prostitutes and club prostitutes in Belgium ( $n=154$ )

\begin{tabular}{|c|c|c|c|}
\hline & $\begin{array}{l}\text { Window prostitutes } \\
n=34\end{array}$ & $\begin{array}{l}\text { Club prostitutes } \\
n=120\end{array}$ & p-value \\
\hline $\begin{array}{l}\text { Mean age }\left(\mathrm{SD}^{\star}\right) \\
\text { Mean years of prostitution }(\mathrm{SD}) \\
\text { Mean age of school leave }(\mathrm{SD}) \\
\text { Mean number clients/week }(\mathrm{SD}) \\
\% \text { STD-markers }(\mathrm{n}=100 \%) \\
\text { Condom use: } \% \text { yes to question } \dagger(\mathrm{n}=100 \%) \\
\text { Belgian nationality } \\
\text { Other European nationality } \\
\text { North African nationality } \\
\text { West and Central African nationality }\end{array}$ & $\begin{array}{l}34 \cdot 5(7 \cdot 4) \\
6 \cdot 6(6 \cdot 1) \\
17 \cdot 6(6 \cdot 5) \\
18 \cdot 8(11 \cdot 9) \\
34 \cdot 6 \%(26) \\
27 \cdot 3 \%(33) \\
19(55 \cdot 9 \%) \ddagger \\
10(29 \cdot 4 \%) \ddagger \\
3(8 \cdot 8 \%) \ddagger \\
2(5 \cdot 9 \%) \ddagger\end{array}$ & $\begin{array}{l}34 \cdot 5(7 \cdot 6) \\
7 \cdot 3(6 \cdot 6) \\
15 \cdot 9(3 \cdot 5) \\
12 \cdot 7(7 \cdot 9) \\
17 \cdot 2 \%(93) \\
45 \cdot 2 \%(115) \\
90(76 \cdot 3 \%) \S \\
15(12 \cdot 7 \%) \S \\
10(8 \cdot 5 \%) \$ \\
3(2.5 \%)\end{array}$ & $\begin{array}{l}\text { NS } \\
\text { NS } \\
\text { NS } \\
<0.001 \\
<0.05 \\
<0.05 \\
<0.05 \\
<0.05 \\
\text { NS } \\
\text { NS }\end{array}$ \\
\hline
\end{tabular}

* Standard deviation

$t$ (do you ever have sex with a client without condom? yes/no)

$\ddagger(\%$ of total window prostitutes $)$

$\$(\%$ of total club prostitutes)

24 women (19.5\%). Two women (1.6\%) had active or recently treated syphilis, and six women (4.9\%) had markers of past syphilis.

Thirty one $(20 \cdot 1 \%)$ women refused to have a blood sample taken, mostly because they were previously tested by their own physician. Since there was no significant difference between this group and the women who accepted blood sampling regarding previous testing for HIV and the other characteristics in the study, both groups were joined for further analysis.

In our study group we describe two different subgroups, window prostitutes and club prostitutes. Window prostitutes attract their clients mainly while they sit behind a window of a little bar, situated in the city centre or along the main roads to neighbouring towns. The interaction with the client is shorter and more directly orientated to sexual acts.

Club prostitutes are not visible from the streets. They create a more general atmosphere where drinking is important, and sexual acts need not always take place. In table 2 we describe a number of social characteristics of both groups. In the group of window prostitutes we find a higher number of clients, more STD seromarkers, more condom use with clients and more prostitutes with a foreign nationality. In club prostitution there are more Belgian women.

We examined the relation between STD markers (any test positive for anti-HIV antibodies, HBsAg, anti-HBc, VDRL or TPHA) and age, years in prostitution, age of leaving school, number of clients, condom use and type of prostitution in a stepwise multiple regression analysis (table 3 ). To avoid possible inclusion of perinatally transmitted HBV markers in the model, we excluded the African women from this analysis. Age was the strongest predictor for STD seromarkers. The type of prostitution was the second predictor. The third factor derived from our data was the number of clients, in a reverse relationship. The more clients are mentioned the less likely are STD seromarkers and vice versa. Professional condom use was not selected as a predictor for STD markers, nor the amount of years in prostitution and the age of leaving school.

Former testing for HIV had been done in $66.5 \%$ (n $=102$ ) of the respondents. There was no difference between window and club prostitutes. In table 4 time of last test and reasons for testing are shown. In the majority, $82.3 \%$, the last test was performed in the year before the interview. In $74.5 \%$ the test was performed at the request of the woman herself. In

Table 3 Relative influence of 6 variables on STD-markers ${ }^{\star}$ in a stepwise multiple regression analysis in Belgian and other European prostitutes in Ghent $(n=107)$

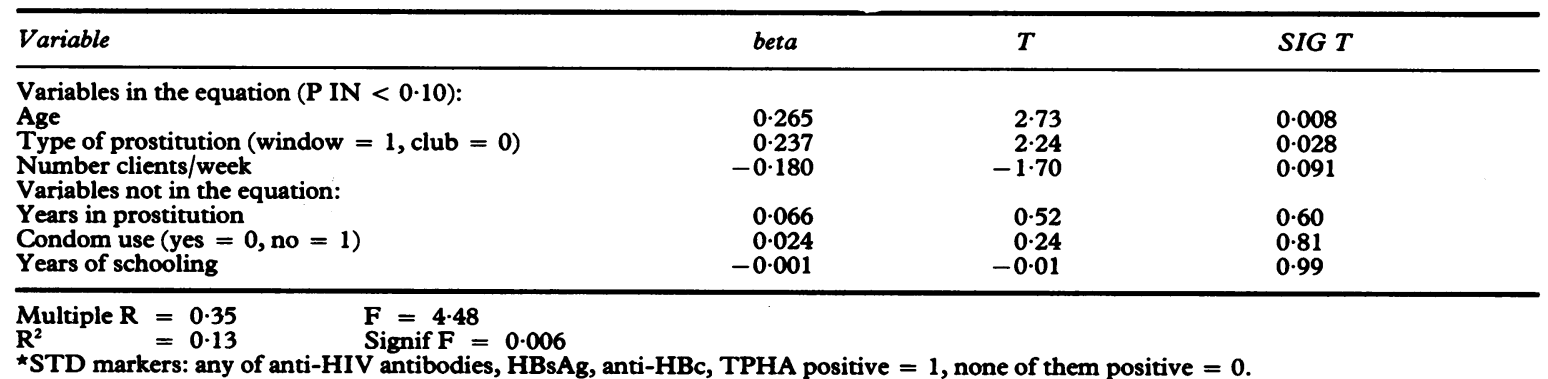


Table 4 Characteristics of testing for HIV in a group of window and club prostitutes previously tested for $H I V$ $(n=102)$

\begin{tabular}{|c|c|c|}
\hline Time of last HIV test: & $N$ & Percentage \\
\hline $\begin{array}{l}\text { Year before interview } \\
\text { Two years before interview } \\
\text { Three years before interview }\end{array}$ & $\begin{array}{r}84 \\
14 \\
4\end{array}$ & $\begin{array}{r}82 \cdot 3 \% \\
13 \cdot 7 \% \\
3 \cdot 9 \%\end{array}$ \\
\hline Total & 102 & $100 \%$ \\
\hline $\begin{array}{l}\text { Reasons for having a HIV test: } \\
\text { I want to protect myself } \\
\text { I want to protect others } \\
\text { I asked for it myself } \\
\text { The doctor advised me to } \\
\text { I needed an operation }\end{array}$ & $\begin{array}{r}90 \\
80 \\
76 \\
28 \\
9\end{array}$ & $\begin{array}{r}88 \cdot 2 \% \\
78.4 \% \\
74.5 \% \\
27.5 \% \\
8.9 \%\end{array}$ \\
\hline
\end{tabular}

^Interview 1989.

$61.6 \%$ the general practitioner performed the test, in $19.2 \%$ the hospital, and in $18.2 \%$ the gynaecologist. Seventy three $(71 \%)$ women said they felt safer after a test. Sixty women $(59 \%)$ mentioned at least to one client that they had been tested, while in $\mathbf{4 0}$ cases $(26 \%)$ at least one client asked the woman whether she had been tested. Clients of club prostitutes asked this question significantly $(p<0.01)$ more often than clients of window prostitutes.

When asked whether an HIV test on a three monthly basis would be advisable for prostitutes, $80 \%$ agreed, and $84 \%$ found it a good idea to test clients in the same way.

Information on other STD was obtained orally by the interviewers, who were not medically trained. Only 100 women gave an answer, of which $21.0 \%$ had a history of STD. Treatment was given by a general practitioner in about half of the cases, and by a gynaecologist in the other half. About $75 \%$ of them were aware of the woman's profession in the sex industry. Further information obtained in the interview on STD was not considered reliable.

Of the tested women, $78(64 \%)$ phoned for the results, including the seropositive woman, who was counseled and referred to a specialised centre.

There was no difference in schooling and STD seromarkers between the women who phoned and those who did not. Significantly more calls came in from women who worked longer as a prostitute (p $<0.05)$, who had Belgian nationality ( $<<0.01)$ and who worked in clubs instead of behind windows $(\mathrm{p}<0.05)$.

\section{Discussion}

Many studies of prostitutes have been made on women in prisons, STD clinics, or in centres specifically dealing with prostitutes. ${ }^{3-7}$ The problem of selection exists in all these studies. We tried to overcome selection problems by choosing a recruit- ment system through contact persons, and by going to the women instead of asking the women to come to the research centre. Another advantage of this approach is the development of confidence between the contact persons and the respondents, which may lay a base for future intervention projects. The visit of the doctor gave ample opportunity to discuss several issues that were raised in the interview session, such as multiple testing for HIV.

We estimate the total number of club and window prostitutes in our area (about 500000 inhabitants) at approximately 500 women. In most places, two or more women work together. Some bars and clubs refused to collaborate, before our team members were able to explain the purpose of the study, which reflects the suspicions entertained. We finally contacted about half of the population under study, geographically well spread, and of them $64 \%$ collaborated. We consider this sample to be fairly representative, though it remains difficult to define the total population when dealing with prostitution.

Intravenous drug use could not be excluded, but there are no arguments to assume a high level of use in our study population.

HIV prevalence in our study was in accordance with other studies among non iv-drug using prostitutes in Europe and the US. ${ }^{8}$ The prevalence of seromarkers for Hepatitis B and syphilis, were similar to those reported from Antwerp in Belgium. ${ }^{9}$ From these data we conclude that HIV-infection is not yet prevalent in non-intravenous drug using prostitutes in Belgium, but that this situation may change considering the rates of STD seromarkers found, which are higher than in the general population in Belgium.

The two persons with anti-HBc alone may be in the windowphase of the infection, or are low responders for anti-HBs. The persons with anti-HBs alone may be vaccinated. The vaccine is easily available on the Belgian market. We did not verify this with the respondents.

The most important route of transmission for HCV is through intravenous drug use or the transfusion of blood and blood products. ${ }^{10}$ The three women with HCV from our study did not report blood transfusions. Since in this study the possibility of past intravenous drug use may not be excluded, we cannot decide whether intravenous drug use or sexual transmssion was responsible for $\mathrm{HCV}$.

We describe two types of prostitution and examine their relation to the prevalence of STD seromarkers. In this analysis we did not consider African prostitutes. The probability that they had perinatally transmitted HBV cannot be excluded. In Belgian and other European prostitutes we consider seromarkers for HBV to be mainly transmitted through sexual contact, although previous intravenous drug use could not be excluded. From the stepwise multiple 
regression analysis we conclude that window prostitution is an independent risk factor for getting a STD. The number of clients shows an inverse relationship with the risk of getting a STD. Reported condom use with clients was not significantly related to STD risk. Window prostitutes might be more at risk, not because they use less condoms, or have more clients, but because their clients belong to a higher STD risk group themselves. So was the issue of AIDS significantly less often raised by their clients in comparison to the clients of the club prostitutes? Future research should therefore also be focussed on the client.

Information on STD was difficult to objectivate without proper testing. Not medically trained, the contact persons did not feel confident in STD history taking.

The amount of women who tested for HIV at least once is surprisingly high: $102(66.5 \%)$. Antwerp reports $57 \%$ of 83 women. ${ }^{9}$ Testing has apparently become the norm in this population in Belgium. For $74.5^{\circ}{ }_{0}$ it was the woman herself who requested the test, which means that it is not the doctor who imposes testing for this group of people. If asked whether testing is useful for prostitutes, $80 \%$ gave a positive answer, in accordance with their actual behaviour. More than $88 \%$ said: "I want to protect myself'. Sixty percent of the women sometimes tell their clients that they are tested. We consider this attitude as a possible danger in the prevention of STD and HIV. If the importance of testing tends to be overemphasised, some women may not feel the need for condom use as strongly as necessary. The argument of a negative test may be used by the client to refuse the use of a condom.

Our study shows a low prevalence of HIV in non drug using prostitutes in Belgium, a relatively high level of STD seromarkers, and a tendency for multiple testing for HIV. Health education messages should clearly discourage the notion of testing as an alternative for using condoms.

This study was financed by a grant from the AIDSreference centre Ghent.

We especially thank the contact persons Terry Baele and Dille; and to Sylvie Dinakis, for laboratory testing and administration.

Address for correspondence: Dr R Mak, Department of Hygiene and Social Medicine, University Hospital, Block A, De Pintelaan 185, 9000 Ghent, Belgium.

1 Institute for Hygiene and Epidemiology, Ministry of Health, 1989, AIDS-Bulletin 18.

2 Sabbe L, Thienpondt L, Mak R, et al. Prevalentie en risicofactoren van AIDS bij risicogroepen: druggebruikers en prostituees. Tijdschrift voor Geneeskunde, 1988;44, 22:1525-8.

3 Darrow WW. Prostitution and sexually transmitted diseases. In: Holmes KK, Mardh P-A, Sparling PF, Wiesner PJ, eds Sexually Transmitted Diseases. New York: McGraw-Hill, 1984:109-16.

4 Bradbeer CS, Thin RN, Tan T, Thiromoorty T. Prophylaxis against infection in Singaporian prostitutes. Genitourin Med 1988;64:52-3.

5 Wooley PD, Bowman CA, Kinghorn GR. Prostitution in Sheffield: differences between prostitutes. Genitourin Med 1988;64:391-3.

6 Hartcourt C, Philpot R, Edwards J. The effect of condom use by clients on the incidence of STD in female prostitutes. Venereology 1989;2:4-7.

7 Van Den Hoek JAR, Van Haastrecht HJA, Scheeringa-Troost B, Goudsmit J, Coutinho RA. HIV-infection and STD in drug addicted prostitutes in Amsterdam: potential for heterosexual transmission. Genitourin Med 1989;65:146-50.

8 Piot $P$, Laga M. Prostitutes: a high risk group for HIV infection? Soz-Praventivmed 1988;33:336-9.

9 Praats C, Laga M, Van Royen P, Peeters M, Hendrickx C, Piot P. Female prostitutes in Antwerp: a risk group for HIV infection. Abstract M.A.P.49, 5th International Conference on AIDS, Montreal 1989.

10 Esteban JI, et al. Hepatitis C Virus Antibodies among risk groups in Spain, Lancet 1989;ii:294-6. 